\title{
A comparison of rate and uniformity of embryo development in Meishan and European white pigs
}

\author{
I. Wilmut ${ }^{1}$, W. A. Ritchie ${ }^{1}$, C. S. Haley ${ }^{1}$, C. J. Ashworth ${ }^{2}$ and R. P. Aitken ${ }^{2}$ \\ ${ }^{1}$ AFRC Institute of Animal Physiology and Genetics Research, Edinburgh Research Station, Roslin, \\ Midlothian, EH25 9PS, UK and; ${ }^{2}$ Rowett Research Institute, Bucksburn, Aberdeen AB2 9SB, UK
}

\begin{abstract}
Summary. A comparison was made of the rate and uniformity of development of embryos recovered from Meishan and European white sows. The time of ovulation was estimated to be 34.3 and $49.0 \mathrm{~h}$ after the onset of oestrus in large white and Meishan sows, respectively. Embryos were recovered from a total of 38 Meishan and 37 European pigs between 18 and $219 \mathrm{~h}$ after the estimated time of ovulation. Embryos recovered after $18-59$ or $44-82 \mathrm{~h}$ were classified into one of 11 stages (from early fertilization to early blastocyst), and the maximum blastocyst diameter was measured for embryos recovered $140-219 \mathrm{~h}$ after ovulation. There was no evidence of a difference between the genotypes in the stage or size of embryos at these times or of large differences between the genotypes in the extent of variation in embryo stage within females, although a minority of European white females had very variable embryos. As the differences between the embryos of the Meishan and the European white were small, it seems unlikely that greater uniformity of Meishan embryo development is a major cause of the higher prenatal survival in that breed.
\end{abstract}

Keywords: pigs; prenatal survival; embryo development

\section{Introduction}

The Chinese Meishan pig is exceptionally prolific, having approximately four more live piglets per litter than the large white (Bidanel et al., 1989; Haley \& Lee, 1990). Populations of Meishan pigs have been established in several countries with a view either to exploiting their prolificacy in crossbreeding programmes or to discovering the mechanism underlying the prolificacy in Meishan females and ultimately to using methods of gene manipulation to introduce a similar genetic change into other breeds.

The higher prolificacy in Meishan females has been shown to reflect primarily a higher prenatal survival at a given number of ovulations, although the Meishan also has a greater number of ovulations (Haley \& Lee, 1990). Crossbreeding studies show that the prolificacy is a result of genes acting in the mother (Bidanel et al., 1989; Haley \& Lee, 1990), but it is not known whether the effect occurs via the oocyte or uterus. In an earlier study of embryo development in Meishan pigs imported into France, blastocyst development between days 8 and 12 was more rapid and more uniform in Meishan than large white gilts and it was suggested that factors controlling blastocyst development may be primary determinants of the prolificacy (Bazer et al., 1988).

The establishment of pregnancy depends upon an appropriate relationship between mother and embryo. There are three facets to this relationship: (i) a sequence of uterine secretions is essential for normal embryo development; (ii) signals from the embryo at particular stages of development are required for the establishment of pregnancy; and (iii) it is essential that the two develop in synchrony. It has been suggested that spontaneous variation in the rate of embryo development, the pattern of hormone secretion and consequently of uterine function or the synchrony between 
the two may be sufficient to prejudice prenatal survival (Wilmut et al., 1986; Pope et al. 1990). Under this hypothesis, reduced variation in embryo stage within a female, as reported by Bazer et al. (1988) in a Meishan population, might be expected to enhance survival by enabling a higher proportion of embryos to be at an appropriate stage of development for the maternal environment (Wilmut et al., 1986; Pope et al., 1988). Although experimental perturbation of the relationship between embryo and mother, either by the administration of hormones or transfer of embryos to recipient females at a different stage of the oestrous cycle to the donor females, may cause a reduction in survival, there are few reports of an increase in survival following treatments to modify the relationship. In addition to the potential commercial value of the Meishan pig, they may also be a unique experimental model for the study of the relationship between embryo and mother.

The present study was carried out to compare the rate and uniformity of embryo development in Meishan and European white pigs, which were known to differ in prenatal survival. The objective was to test the hypothesis that the higher prolificacy of the Meishan female was associated with more uniform blastocyst development and to determine the stage at which the greater uniformity arises by comparing development at earlier stages. In these studies, pure-bred Meishan pigs carrying pure or crossbred embryos were compared with pure or crossbred European females carrying pure or crossbred embryos. As previous trials (Bidanel et al., 1989; Haley \& Lee, 1990) have shown that the difference in prolificacy between Meishan and European pigs is much greater than any difference between the European breeds or their crosses and that the differences between Meishan and European pigs are controlled by genes acting in the mother, any effect of breed of European pig or of crossing in the embryo is of little relevance to the major comparison between Meishan and European females.

Some results from these experiments have been presented at meetings (Ritchie et al., 1989; Haley et al., 1990; Wilmut et al., 1990).

\section{Materials and Methods}

\section{Animals and data collection}

Al! Meishan pigs were bred at the Institute of Anima! Physiology and Genetics Research (IAPGR), Roslin. European white females at IAPGR were sows from the large white breed, whereas those at the Rowett Research Institute (RRI) were Landrace $\times$ large white gilts.

Experiment 1. To estimate the time of ovulation in the two breeds, we examined groups of Meishan and large white sows at IAPGR by laparoscopy 30,40 or $50 \mathrm{~h}$ after the onset of oestrus. Fifteen second parity Meishan and ten large white sows were weaned $28-35$ days after parturition and observed daily in the presence of a boar at midnight, 08.00 and $16.00 \mathrm{~h}$, until the onset of oestrus. Groups of five sows of each breed were examined at 30 and $40 \mathrm{~h}$ and an additional group of five Meishan sows was examined after $50 \mathrm{~h}$.

Experiment 2. The stage of embryo development was determined at three periods between 18 and $219 \mathrm{~h}$ after the estimated time of ovulation. At the IAPGR, second parity Meishan and large white sows were weaned and observed for the onset of oestrus as in Expt 1. They were mated to large white boars at the onset of oestrus and again 16 or $24 \mathrm{~h}$ later. It has previously been shown that the breed of sire has no effect upon prolificacy in Meishan pigs (Bidanel $e t$ al., 1989; Haley \& Lee, 1990); embryos recovered after such mating will therefore provide a measure of the rate and uniformity of development associated with the difference in prolificacy. The sows were killed $18-59 \mathrm{~h}$ (group $2 \mathrm{a}$ ) or $140-219 \mathrm{~h}$ (group $2 \mathrm{c}$ ) after the estimated time of ovulation. The reproductive tracts were transported to the laboratory at ambient temperature. The number of ovulations was determined by dissecting the ovaries. Sterile isotonic $\mathrm{NaCl}$ solution was flushed through the oviduct (group 2a) or uterus (group 2c) to allow embryo recovery.

At the Rowett Research Institute, embryo transfer was carried out within and between Meishan and European white pigs to define the role of oocyte and uterus in the prolificacy of Meishan pigs (Ashworth et al., 1990) and the stage of embryo development was recorded at the time of transfer (group 2b). Details of the experimental protocol are presented elsewhere (Ashworth et al., 1990). Briefly, gilts aged 7-8 months were penned individually and fed $20 \mathrm{mg}$ allyltrenbolone (Regumate: Hoechst, Hounslow, Middlesex, UK) for 18 days. At the time of treatment the Meishan and Landrace $x$ large white gilts had experienced four or five and two or three oestrous cycles, respectively. After the treatment, the gilts were observed twice daily in the presence of a boar at 08.00 and $16.00 \mathrm{~h}$, respectively. At the onset of oestrus, and $12 \mathrm{~h}$ later, Meishan and Landrace $\times$ large white donor gilts were mated to two different boars of the same breed (Meishan and large white, respectively). The number of ovulations in donor females was estimated by counting the corpora lutea visible on the surface of the ovary at the time of surgery, $4482 \mathrm{~h}$ after the estimated time 
of ovulation. As the difference in prolificacy between the white pigs and their crosses is small in comparison with the difference between white pigs and the Meishan pigs (Sellier, 1976), observations with these crossbred females and embryos are expected to provide an accurate indication of the role of any difference in uniformity or rate of embryo development in the unusual prolificacy of the Meishan pig.

Embryos recovered between 18 and $82 \mathrm{~h}$ after the estimated time of ovulation (groups $2 \mathrm{a}$ and $2 \mathrm{~b}$ ) were examined by bright field microscopy with maximum magnification of $100 \times$ and classified on an 11-point scale (Table 1). The minimum and maximum diameters of embryos recovered $140-219 \mathrm{~h}$ after ovulation (Group $2 \mathrm{c}$ ) were measured using phase contrast microscopy.

Table 1. Classification of developmental stages of conceptuses recovered $18-82 \mathrm{~h}$ after ovulation

\begin{tabular}{ll}
\hline Classification & \multicolumn{1}{c}{ Developmental stage } \\
\hline 1 & One cell-early post-fertilization \\
2 & One cell-early pronuclear \\
3 & One cell-late pronuclear \\
4 & One cell-syngamy \\
5 & Two cell \\
6 & Three-four cells \\
7 & Five-eight cells \\
8 & More than eight cells \\
9 & Morula \\
10 & Compact morula \\
11 & Early blastocyst \\
\hline
\end{tabular}

\section{Statistical analyses}

Experiment 1. Time from observed onset of oestrus to ovulation was analysed as a binary trait (ovulated or not ovulated) using the computer package GLIM (Baker \& Nelder, 1978). Onset of oestrus was assumed to have occurred midway between the time at which oestrus was first observed and the previous observation at which the animal was not in oestrus (i.e. $4 \mathrm{~h}$ before the first observation of oestrus). The trait was analysed fitting breed and estimated time between the onset of oestrus and laparoscopy as a covariate. From this fitted model the time at which half of the females in each breed would have ovulated was predicted.

Experiment 2-time of ovulation. The interval between ovulation and time of conceptus measurement was estimated for each female. Onset of oestrus was assumed to have been at the midpoint between the last observation at which oestrus was not observed and the first observation of oestrus. The interval was estimated as the time between the assumed onset of oestrus and the time of killing or conceptus recovery minus $34.3 \mathrm{~h}$ in the large white breed and minus 49.0 in the Meishan breed. (The hours subtracted are those estimated as the interval between the onset of heat and ovulation in the two breeds as estimated in this study.) Analyses of ovulation rate, number of recovered conceptuses, proportion of corpora lutea represented by recovered conceptuses and estimated interval between ovulation and conceptus measurement were performed using GLIM assuming normality. The effect of breed was estimated for all traits as was the effect of ovulation rate for the proportion of corpora lutea represented by recovered conceptuses.

Experiment 2-rate of embryo development. Analyses of rate of development of maximum or average conceptus diameter 140-219 h after the estimated time of ovulation (group 2c) were performed using GLIM assuming normality after transformation of the data to natural logarithms to remove a relationship between the mean and variance. Analyses of rate of development of conceptuses classified by stage at 18-59 and 44-82 h after the estimated time of ovulation (group $2 \mathrm{a}$ and $2 \mathrm{~b}$ data respectively, see Table 1) were performed using GLIM assuming normality. Effects tested were genotype of female, estimated interval between ovulation and conceptus measurement and the interaction between these two factors. Significance of these between female effects was tested using a variance ratio test against the residual between female variation after fitting the effects, rather than against the (smaller) within female between conceptus variation.

Analysis of the data classified according to stage by methods assuming a normal model may not be wholly appropriate (group $2 \mathrm{a}$ and $2 \mathrm{~b}$ observations made from $18-59$ and $44-82 \mathrm{~h}$ after the estimated time of ovulation). To confirm the results from these analyses we also analysed the data as a categorical trait, with the observations from each gilt or sow categorized as the number of conceptuses in each of the developmental classes. These data were analysed using GLIM assuming a Poisson error (approximately equivalent to an analysis of a contingency table). In addition to the inclusion of the marginal totals as required in this type of analysis (i.e. totals for individual females and conceptus developmental stages), the interaction of developmental stage with estimated interval between ovulation and conceptus measurement was included in the model to test whether the number in each developmental stage alters with the 
estimated interval. To test for a difference between genotype of female we analysed the interaction between genotype of female and developmental stage and the interaction between genotype of female, developmental stage and estimated interval between ovulation and conceptus measurement were also included in this model. The former effect tests for a difference in developmental stages between genotype of female after adjustment for the estimated interval between ovulation and conceptus measurement and the latter effect tests whether the relationship between the estimated interval and developmental stage differs between the two genotypes (e.g. owing to different rates of development). The significance of all interaction terms was tested against the chi-squared distribution with the appropriate degrees of freedom.

Experiment 2 -within female variation in rate of embryo development. The total within female variance in the developmental stage of conceptuses from 18-59 and 44-82 h after the estimated time of ovulation and of logtransformed maximum conceptus diameter from 140-219 h data were calculated for each genotype separately. The ratio of the variances for each genotype from each of the three data sets was tested against a two-tailed distribution to assess a difference between the genotypes in the within female variance.

An alternative assessment of the within female variation in the developmental stage classified data from $18-59$ and $44-82 \mathrm{~h}$ was made after analysis of the data as a categorical trait. Breeds were analysed separately. In these analyses the model included individual female and conceptus developmental stage and the interaction between developmental stage and the mean developmental stage of conceptuses within a female. In this model, residual variation will represent variation at about the mean stage of development of embryos collected from a single female. The deviation of the fitted numbers at each developmental stage from the observed numbers was accumulated over females from one genotype at one sample period in one group (either $2 \mathrm{a}$ or $2 \mathrm{~b}$ ).

\section{Results}

\section{Time of ovulation}

In the large white group, two of five sows had ovulated when examined $30 \mathrm{~h}$ after oestrus was first observed and all five had ovulated $40 \mathrm{~h}$ after oestrus was first observed. None of the five Meishan sows had ovulated when examined at either 30 or $40 \mathrm{~h}$ after oestrus was first observed, although all five had ovulated when observed $50 \mathrm{~h}$ after oestrus was first observed. The predicted time after the onset of oestrus at which $50 \%$ of sows would have ovulated was $34.3 \mathrm{~h}$ in the large white and $49 \cdot 0 \mathrm{~h}$ in the Meishan breed. Thus the estimated difference between the two breeds is $14 \cdot 7 \mathrm{~h}$.

\section{Embryo development}

Development after 18-59h (group 2a). Embryos from nine Meishan sows and 13 large white sows were assessed. The estimated interval between ovulation and conceptus measurement varied between 27.0 and $51.0 \mathrm{~h}$ in the Meishan sows and between 17.7 and $58.7 \mathrm{~h}$ in large white sows. The mean estimated interval between ovulation and conceptus measurement was $37 \cdot 0 \pm 2 \cdot 1 \mathrm{~h}$, with no significant difference between breeds.

The breed difference in number of ovulations was significant $(P=0 \cdot 01-0 \cdot 001)$ as was that for the number of conceptuses recovered $(P<0.001)$ (Table 2). The proportion of corpora lutea represented by recovered conceptuses was not significantly different between breeds $(-0.077 \pm 0.056)$. The regression of this proportion on the number of ovulations was not significantly different from zero $(0.000 \pm 0.006)$ and adjusting for number of ovulations did not alter the estimate of the breed difference.

The overall mean developmental stage of conceptuses estimated in the analysis assuming normal errors was $5 \cdot 30 \pm 0 \cdot 27$. There were significant linear $(0 \cdot 406 \pm 0 \cdot 121)$ and quadratic $(-0.00431 \pm 0.00159)$ regressions of conceptus developmental stage on estimated interval between ovulation and conceptus measurement (Fig. 1). There was no significant difference between the breeds and the regression on estimated interval between ovulation and conceptus measurement did not differ between the breeds.

Conclusions from the analysis of the data in categorical form were the same. There was a significant interaction between estimated interval between ovulation and conceptus measurement 
Table 2. The effect of breed on the number of ovulations, number of conceptuses recovered and the proportion of ovulations represented by a recovered conceptus at each of the three experimental periods

\begin{tabular}{|c|c|c|}
\hline & Meishan & European \\
\hline \multicolumn{3}{|l|}{ Group $2 a(18.59 h)^{a}$} \\
\hline Number of animals & 9 & 13 \\
\hline Number of ovulations & $26.0 \pm 1.7$ & $18.9 \pm 1.4$ \\
\hline Number of conceptuses & $21.8 \pm 1.7$ & $13.4 \pm 0.04$ \\
\hline $\begin{array}{l}\text { Number of conceptuses: } \\
\text { number of ovulations }\end{array}$ & $0.94 \pm 0.04$ & $0.86 \pm 0.04$ \\
\hline \multicolumn{3}{|l|}{ Group $2 b(44-82 h)^{\mathrm{b}}$} \\
\hline Number of animals & 15 & 17 \\
\hline Number of ovulations & $20.9 \pm 0.9$ & $16.8 \pm 0.8$ \\
\hline Number of conceptuses & $21 \cdot 4 \pm 1 \cdot 1$ & $15 \cdot 3 \pm 1 \cdot 1$ \\
\hline $\begin{array}{l}\text { Number of conceptuses: } \\
\text { number of ovulations }\end{array}$ & $1.03 \pm 0.04$ & $0.92 \pm 0.04$ \\
\hline \multicolumn{3}{|l|}{ Group $2 c(140-219 h)^{\mathrm{a}}$} \\
\hline Number of animals & 14 & 7 \\
\hline Number of ovulations & $26 \cdot 4 \pm 1 \cdot 3$ & $17 \cdot 1 \pm 1.9$ \\
\hline Number of conceptuses & $18 \cdot 2 \pm 1 \cdot 3$ & $11.9 \pm 1.8$ \\
\hline $\begin{array}{l}\text { Number of conceptuses: } \\
\text { number of ovulations }\end{array}$ & $0.74 \pm 0.05$ & $0.77 \pm 0.06$ \\
\hline
\end{tabular}

${ }^{\mathrm{a}}$ In groups $2 \mathrm{a}$ and $2 \mathrm{c}$ the females were all second parity sows, ${ }^{b}$ whereas in group $2 b$ the females were gilts. The European females were large white in groups $2 a$ and $2 c$, but Landrace $\times$ large white in Group $2 b$.

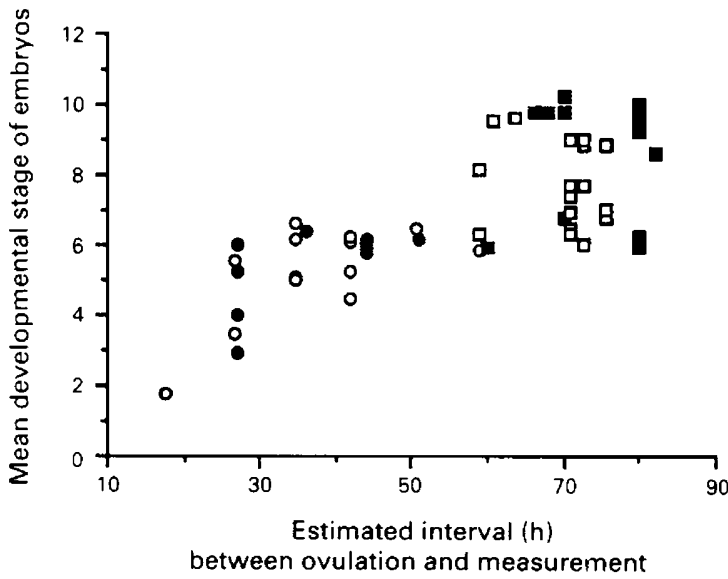

Fig. 1. The mean developmental stage of embryos from each female killed $18-82 \mathrm{~h}$ after the estimated time of ovulation shown against estimated interval between ovulation and conceptus recovery (Expt 2 - groups 2a and 2b). (O): Meishan (18-59 h); ( $\mathbf{\square})$ : Meishan (44-82 h); (O): European white (18-59 h); ( $\square)$ : European white (44-82 h).

and conceptus developmental stage. There was no significant interaction of breed with conceptus developmental stage or interaction of breed, conceptus developmental stage and estimated interval between ovulation and conceptus measurement. 
The total within female variance in conceptus developmental stage was $0 \cdot 145$ (d.f. 187) in Meishan sows and 0.331 (d.f. 161) in large white sows. The variance ratio was $2 \cdot 28$, with two-tailed probability, $P<0.001$. Any difference in female standard deviations of conceptus developmental stage versus mean conceptus developmental stage between genotypes is due to three large white sows with high standard deviation of conceptus developmental stage.

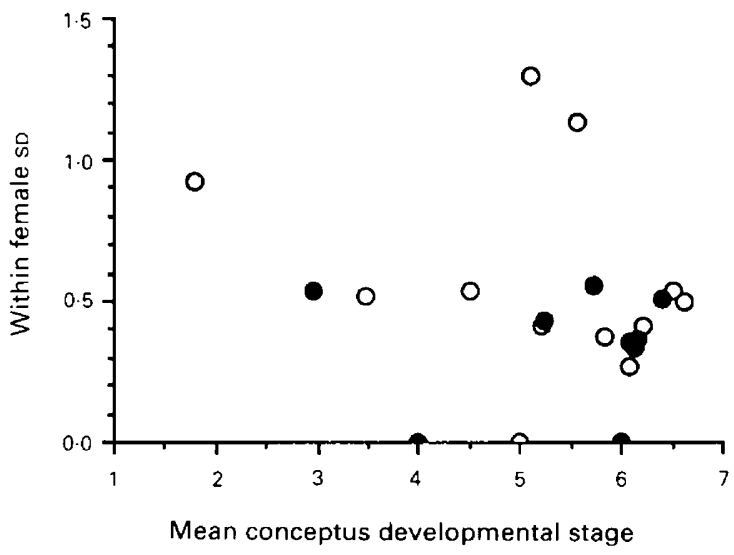

Fig. 2. The individual within-female standard deviations of conceptus developmental stage for those animals killed $18-59 \mathrm{~h}$ after the estimated time of ovulation are plotted against mean conceptus developmental stage (group 2a). (๑): Meishan; $(\bigcirc)$ : large white.

The analysis of the data as a categorical trait and including individual female, conceptus developmental stage and the interaction between conceptus developmental stage and mean conceptus developmental stage produced residual chi-squared statistics of 20.9 (34 d.f.) and 52.2 ( 66 d.f.) in the Meishan and large white genotypes, respectively. In a well-fitting model, the residual chi-squared is expected to be approximately equal to its degrees of freedom, with large values indicating failure of the model to describe the data (Baker \& Nelder, 1978) adequately. Both of the estimated statistics are slightly less than their degrees of freedom, suggesting that once differences between females are allowed for, residual within female variation is similar in the two genotypes. Comparison of the observed with the fitted values shows that the two most deviant conceptuses were from the large white genotypes, but no strong tendency for less deviance in the Meishan than in the large white genotypes is apparent (Fig. 3).

Development after 44-82 h (group 2b). Embryos from 15 Meishan gilts and 17 Landrace $\times$ large white gilts were assessed. The estimated interval between ovulation and conceptus measurement varied between 44.0 and $82.0 \mathrm{~h}$ in the Meishan gilts and between 58.7 and $75.7 \mathrm{~h}$ in Landrace $\times$ large white gilts. The mean estimated interval between ovulation and conceptus measurement was $71.5 \pm 1.5 \mathrm{~h}$, with no significant difference between breeds.

The difference between genotypes in number of ovulations was significant $(P=0.01-0.001)$ as was that for the number of conceptuses recovered $(P<0.001)$ (Table 2$)$. The proportion of corpora lutea represented by recovered conceptuses was $1.03 \pm 0.04$ from Meishan gilts and $0.92 \pm 0.04$ from Landrace $\times$ large white gilts, a nonsignificant difference. The proportion of corpora lutea represented by recovered conceptuses was not significantly different between the genotypes $(-0.113 \pm 0.061)$ and the regression of this proportion on number of ovulations was not significantly different from zero $(-0.001 \pm 0.009)$ and adjusting for number of ovulations altered the estimate of the genotype difference only slightly $(-0 \cdot 116 \pm 0 \cdot 073)$.

The overall mean developmental stage of conceptuses estimated in the analysis assuming normal errors was $8 \cdot 18 \pm 0 \cdot 27$. The linear and quadratic components of the regression of conceptus 


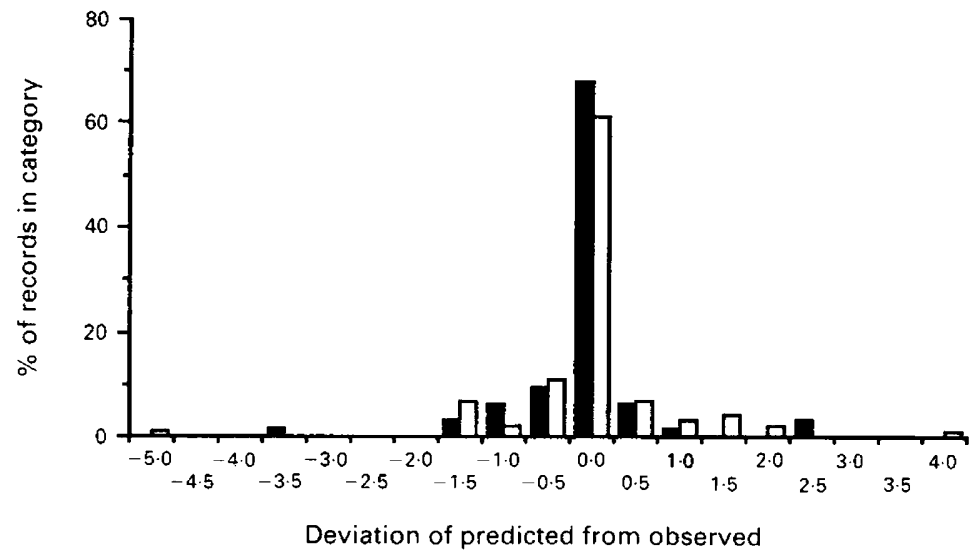

Fig. 3. Variation of embryo developmental stage within females estimated as the residual variation after analysis of the data as a categorical trait in those animals killed $18-59 \mathrm{~h}$ after the estimated time of ovulation (group 2a). ( $\square$ ): Meishan breed $(n=63) ;(\square)$ : European white $(n=91)$.

developmental stage on estimated interval between ovulation and conceptus measurement were both nonsignificant, but they were of similar magnitude to those estimated from the 2-3-day data $(0.496 \pm 0.386$ and $-0.00353 \pm 0.00264$, respectively). There was no significant effect of genotype of female and the regression on estimated interval between ovulation and conceptus measurement did not differ between the genotypes.

Conclusions from the analysis of the data in categorical form were the same. The interaction between estimated interval between ovulation and conceptus measurement and conceptus developmental stage was not significant. There was no significant interaction of genotype of female with conceptus developmental stage or interaction of genotype of female, conceptus developmental stage and estimated interval between ovulation and conceptus measurement.

The total within female variance in conceptus developmental stage was 0.279 (d.f. 306) in Meishan gilts and 0.328 (d.f. 247) in Landrace $\times$ large white gilts. The variance ratio was 1.17 and was nonsignificant (Fig. 4).
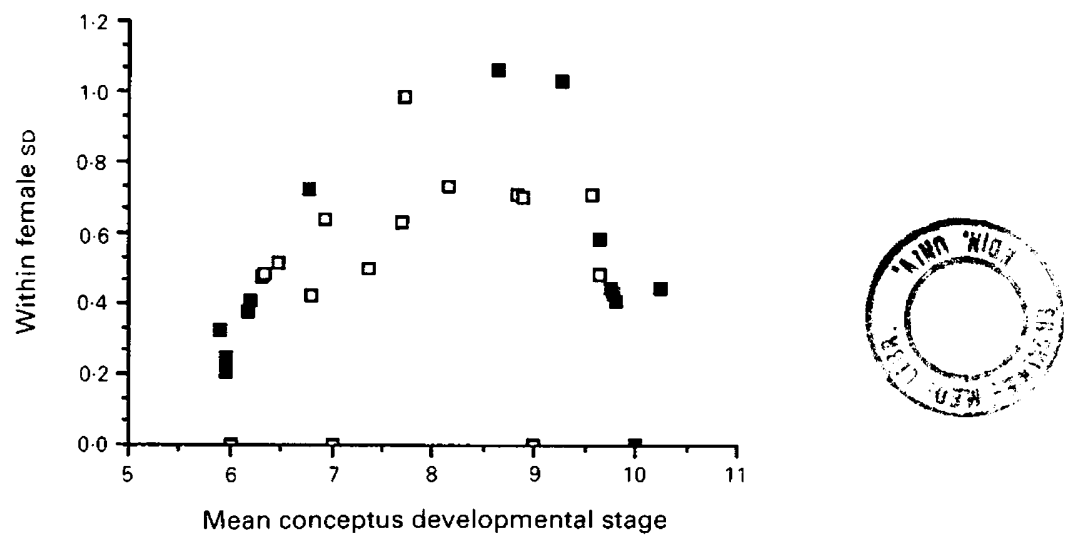

Fig. 4. The individual within-female standard deviations of conceptus developmental stage for those animals killed $44-82 \mathrm{~h}$ after the estimated time of ovulation are shown plotted against mean conceptus developmental stage for those females (group 2b). ( $\mathbf{a}$ ): Meishan breed; ( $\square$ ): European white breed. 
The analysis of the data as a categorical trait and including individual female, conceptus developmental stage and the interaction between conceptus developmental stage and mean conceptus developmental stage produced residual chi-squared statistics of 40.4 ( 74 d.f.) and 102.5 (90 d.f.) in the Meishan and Landrace $\times$ large white gilts, respectively. The deviation of the observed from the fitted values shows that the six most deviant conceptuses were from the Landrace $\times$ large white breed, but there is no overall trend for greater deviance in the Landrace $\times$ large white breed (Fig. 5).

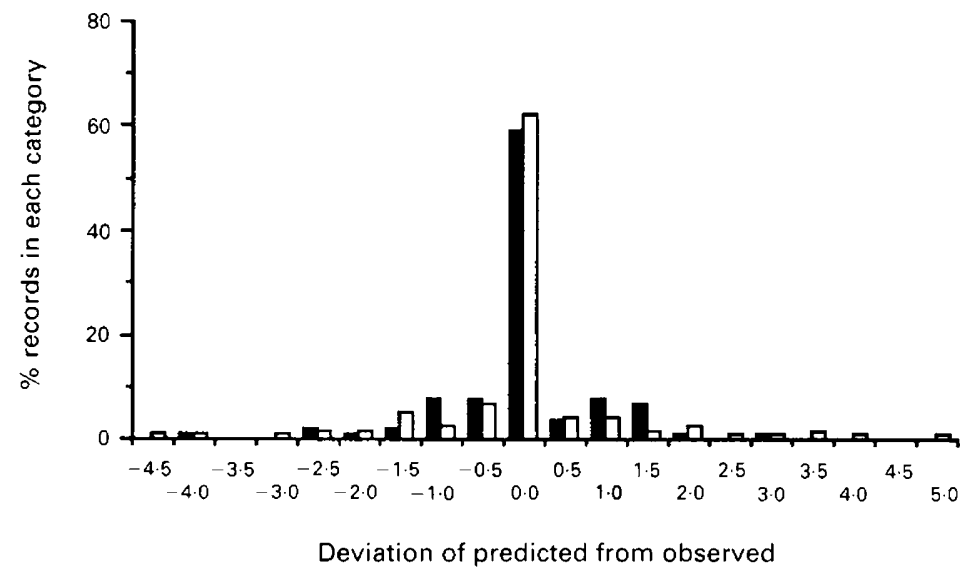

Fig. 5. Variation of embryo developmental stage within females estimated as the residual variation after analysis of the data as a categorical trait in those animals killed $44-82 \mathrm{~h}$ after the estimated time of ovulation (group 2b). ( $\square$ ): Meishan breed $(n=105)$; $(\square)$ ): large white breed $(n=119)$.

Development after 140-219h (group 2c). Embryos from 14 Meishan sows and 7 large white sows were assessed. The estimated interval between ovulation and conceptus measurement varied between 140.0 and $204.0 \mathrm{~h}$ in the Meishan sows and between 161.7 and $218.7 \mathrm{~h}$ in large white sows. The mean estimated interval between ovulation and conceptus measurement was $178.5 \pm 5 \cdot 3 \mathrm{~h}$, with no significant difference between the breeds.

The breed difference in number of ovulations was significant $(P=0.01-0.001)$, as was that for the number of conceptuses recovered $(P=0.05-0.01)$ (Table 2$)$. The proportion of corpora lutea represented by recovered conceptuses was not significantly affected by genotype of female $(0.028 \pm 0.092)$ and the regression of this proportion on number of ovulations was not significantly different from zero $(-0.016 \pm 0.009)$. Although adjusting for number of ovulations changed the sign of the breed difference, it remained nonsignificant $(-0 \cdot 121 \pm 0 \cdot 118)$.

Some of the conceptuses recovered from both breeds were damaged ( 31 of the 339 recovered conceptuses); these were omitted from all further analyses. The number of undamaged conceptuses recovered was $16.9 \pm 1.4$ for Meishan sows and $11.4 \pm 1.9$ for large white sows, the difference was significant $(P=0.050 .01)$.

The overall mean maximum log diameter of conceptuses estimated was $-1 \cdot 050 \pm 0 \cdot 155$. This is equivalent to a geometric mean maximum conceptus diameter of $0.350 \mathrm{~mm}$ (Fig. 6). The linear regression of $\log$ conceptus maximum diameter on estimated interval between ovulation and conceptus measurement was significant $(0.0266 \pm 0.0022)$ and there was no significant difference between the genotypes, and the regression on estimated interval between ovulation and conceptus measurement did not differ between the genotypes (Fig. 6).

The total within female variance of $\log$ maximum conceptus diameter was 0.0406 (d.f. 223) in Meishan sows and 0.0722 (d.f. 73) in large white sows. The variance ratio was 1.78 and highly significant $(P<0.001)$ (Fig. 7). It can be seen that the conceptuses from one large white female 


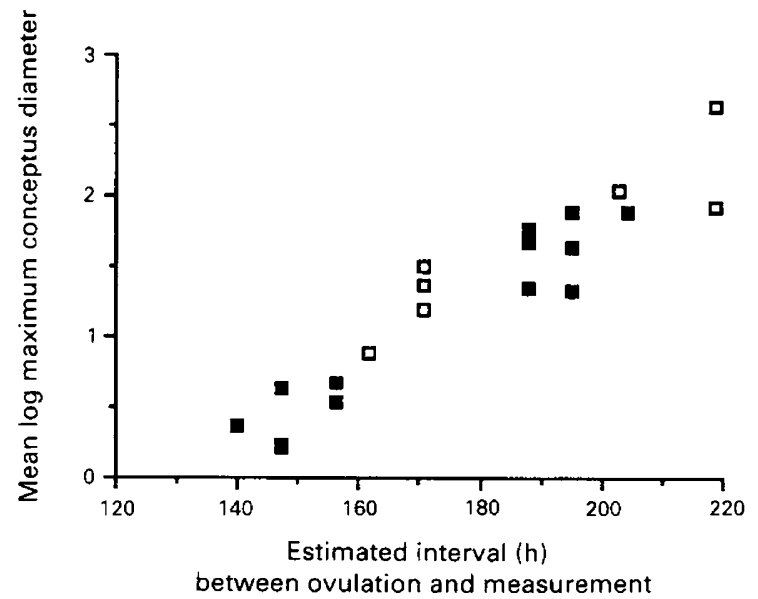

Fig. 6. The mean log maximum diameter of conceptuses from each female killed 140-219h after the estimated time of ovulation is shown against estimated interval between ovulation and conceptus recovery together with the estimated regression (group 2c). ( $\square$ ): Meishan breed; $(\square)$ : European white breed.

were very much more variable than those from other females. If conceptuses from this female were omitted, the total within female variance of maximum conceptus diameter was 0.0464 (d.f. 67) in large white sows; the variance ratio becomes $1 \cdot 14$ and is nonsignificant.

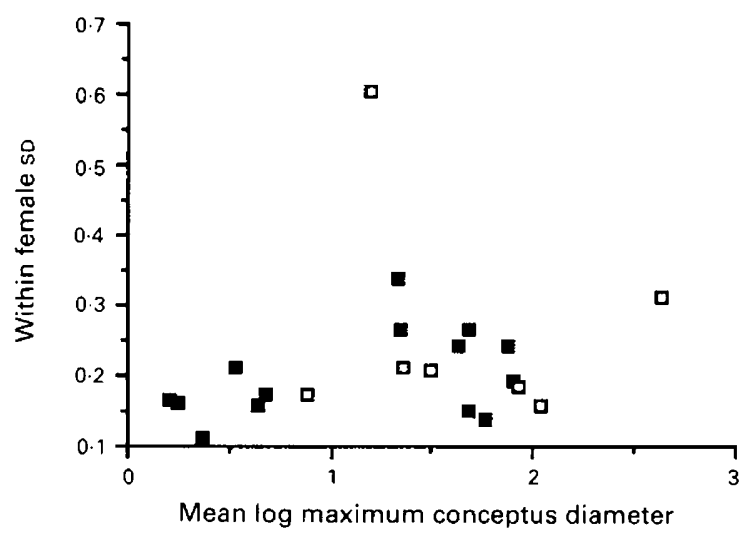

Fig. 7. Individual within-female standard deviations of log maximum conceptus diameter are shown plotted against mean conceptus diameter for females killed $144-219 \mathrm{~h}$ after the estimated time of ovulation (group 2c). ( $\square$ ): Meishan; ( $\square$ ): European white.

Conclusions from the analysis of log average conceptus diameter were similar. The overall mean of log average diameter of conceptuses estimated was $-1.801 \pm 0.077$. This is equivalent to a geometric mean of average conceptus diameter of $0.165 \mathrm{~mm}$. The linear regression of log average conceptus diameter on estimated interval between ovulation and conceptus measurement was significant $(0 \cdot 0268 \pm 0 \cdot 0020)$. There was no significant difference effect of the genotype of female and the regression on estimated interval between ovulation and conceptus measurement did not differ between the genotypes.

The total within female variance of log average conceptus diameter was 0.0351 (d.f. 223) in Meishan sows and 0.0783 (d.f. 73) in large white sows. The variance ratio was 2.23 and highly 
significant $(P<0.001)$. Again it was found that the conceptuses from the one large white female that had been seen as different in the previous analysis were more variable than those from other females. Omitting conceptuses from this female, the total within-female variance of maximum conceptus diameter is 0.0481 (d.f. 67) in large white sows. The variance ratio becomes 1.37 and is nonsignificant.

\section{Discussion}

These observations are in contrast to those from earlier comparisons (Bazer et al., 1988) in that they provide no evidence of a difference between Meishan and European white pigs in the rate of embryo development or embryo survival during the first 10 days after mating and little indication of a large difference between genotypes in the within-female uniformity of embryo development. These conclusions suggest that differences in the pattern of embryo development over this period are unlikely to account for the greater prolificacy of Meishan females.

Analyses of variation in development in the two genotypes are complicated by several factors. First, there is the inherent difficulty and relatively low power of comparisons of variance. Second, the analysis of data up to $82 \mathrm{~h}$ after ovulation is further complicated by the classification of the conceptuses into stages. Thus, it may be inappropriate to consider these data as normally distributed. An alternative, categorical, analysis has also been used, which leads to similar conclusions to those of the analysis based on the assumption of normality. Finally, it is necessary to compare variation within females, for it is only this variation, and not variation between females, that may be associated with asynchrony between embryo and mother.

The present results provided no indication of the large difference in uniformity of embryo development that was reported by Bazer et al. (1988), although there was a tendency for the females with the more variable embryos to be European white. However, the fourfold difference between conceptus variance in the European white and Meishan females observed by Bazer et al. (1988) was not seen in this experiment. It is possible that in the study of Bazer et al. (1988) between female variation was included in the estimate of embryo variation and that this inflated the apparent breed difference and led to biased conclusions. It is unlikely that the small differences between genotypes in the within female conceptus variation that were observed in the present experiments, even if they are real, provide the only explanation of the approximately $20 \%$ difference in prenatal survival, which is observed after adjusting for number of ovulations (Haley \& Lee, 1990).

It might be suggested that the degree of uniformity of embryo development within a female would be reduced as the number of ovulations increased, and that this difference would be associated with a reduction in survival. In the present experiment, there was no association between the variation in conceptus development and the number of ovulations in that female (analysis not presented).

The present experiments do not confirm the French observations of a greater diameter of Meishan embryos recovered on day 10 (compare Fig. 6 with reports of mean diameter of $2.7 \pm 0.8 \mathrm{~mm}$ in Meishan females and $1.9 \pm 0.7 \mathrm{~mm}$ in large white females, Bazer et al., 1988). The difference between the sets of results is greater than it first appears because the present experiment made a correction for the difference between the breeds at the time of ovulation; such a correction was not made by the French researchers - at the same interval after ovulation, the difference between the breeds in the French data was probably greater than reported.

However, the most striking difference between the breeds in the pattern of embryo development that was observed in the first French study was the earlier initiation of elongation in the Meishan embryos (Bazer et al., 1988). Elongated embryos were recovered from three of five and six of six Meishan females killed on days 11 and 12 after oestrus, respectively. By contrast, elongated embryos were not recovered from large white females until day 12 . In the present study, no observations were made on day 11 or 12 . 
There was no evidence in these studies of a difference between the genotypes in survival to the stages of development that were studied. In studies of prenatal survival in pigs, it is important to consider the influence of number of ovulations upon this trait. At any given number of ovulations, prenatal survival was found to be approximately $20 \%$ greater in Meishan females than in large white females. By contrast, the overall prenatal survival (the proportion of ovulations represented by piglets, without correction for the number of ovulations) was very similar in the two breeds. In the present experiment the regression of survival on number of ovulations was zero in group $2 a$, and negative, but not significant, at the later periods studied (groups $2 \mathrm{~b}$ and $2 \mathrm{c}$ ). After adjustment for this regression, survival in European white females was lower than in the Meishan breed, but the breed difference remained nonsignificant.

These experiments provide information on two other aspects of reproduction in the two breeds for which similar comparisons have been made in France. These are: time of ovulation and number of ovulations. The estimates of time of ovulation in the two breeds are very similar to those published previously (Terqui et al., 1990), particularly considering the error in the estimates of the time of the onset of heat and the small number of animals studied. The endocrine mechanism responsible for these differences between the breeds is not known.

In the comparison of the number of ovulations in the two breeds, a consistent difference is emerging between the studies in France and the UK. Comparisons in France show no difference between the breeds or a greater number of ovulations in the large white females (Bolet et al., 1986; Bazer et al., 1988). By contrast, in the UK, the Meishan females have usually been observed to have a greater number of ovulations than large white females, both as gilts and sows, in experiments involving several hundred observations (Haley \& Lee, 1990; Ashworth et al., 1992; the present study). The exceptional observation was in an experiment in which the pigs of both breeds had the same number of oestrous cycles (Biggs et al., 1990). In this case there was no difference between the breeds in the number of ovulations.

Several factors may account for the difference between the studies in the UK and France. First, the Meishan population in France was originally established from two gilts and one boar (Bidanel et al., 1990), compared with 21 females and 11 boars in the importation into the UK. Although there has been an additional importation into France, the present population may not be representative of the Meishan breed as a whole and the two populations may differ because of founder effects. Second, as the animals for the UK and France were obtained from different stock farms they may be derived from different Chinese subpopulations of Meishan pigs. Finally, there may be effects of differences in the environment or nutrition upon the reproductive performance of the pigs. The importance of these and other factors may become apparent as research continues in European and other countries.

The cause of the difference between the breeds in prenatal survival after adjusting for the number of ovulations remains unknown. Crossbreeding studies have revealed that it is a maternal effect (Haley \& Lee, 1990), but it is not clear whether it acts through the ovum, the uterus or both. In an experiment involving embryo transfer within and between the two breed types there was no evidence of an effect of the genotype of the recipient female upon survival to day 30 (Ashworth et al., 1990). However, it seemed that embryos recovered from Meishan females were less tolerant of the transfer procedures that were used because their survival rate was lower than that of large white embryos. Further studies are needed to distinguish between the role of embryo and uterus and to define the stage of pregnancy at which the difference in survival becomes apparent.

We thank the staff of the farm and technical units at IAPGR and RRI for their care of the animals and meticulous recording of the data. Financial support was provided by The British Meishan Consortium (Cotswold Pig Development Company, Masterbreeders (Livestock Development) Company Ltd, National Pig Development Company Ltd, Pig Improvement Company Ltd, United Pig Breeders plc and the Department of Trade and Industry), the Ministry of Agriculture Fisheries and Food and the Department of Agriculture and Fisheries for Scotland. 


\section{References}

Ashworth, C.J., Haley, C.S., Aitken, R.P. \& Wilmut, I. (1990) Embryo survival and conceptus growth following reciprocal embryo transfer between Chinese Meishan and Landrace $\times$ Large White gilts. Journal of Reproduction and Fertility 90, 595-603.

Ashworth, C.J., Haley, C.S. \& Wilmut, I. (1992) Effect of Regumate on ovulation rate, embryo survival and conceptus growth in Meishan and Landrace $\times$ Large White gilts. Theriogenology 37, 433-443.

Baker, R.J. and Nelder, J.A. (1978) The GLIM System. Release 3. Numerical Algorithms Group, Oxford.

Bazer, F.W., Thatcher, W.W., Martinat-Botte, F. \& Terqui, M. (1988) Conceptus development in Large White and prolific Chinese Meishan pigs. Journal of Reproduction and Fertility 84, 37-42.

Bidanel, J.P., Caritez, J.C. \& Legault, C. (1989) Estimation of crossbreeding parameters between Large White and Meishan porcine breeds. 1. Reproductive performance. Génétique Sélection et Evolution 21, 507-526.

Bidanel, J.P., Caritez, J.C. \& Legault, C. (1990) Ten years experiments with Chinese pigs in France. 1. Breed evaluation. Pig News and Information 11(3), 345-348.

Biggs, C., Hunter, M.G., Craigon, J., Wilmut, I., Tilton, J.E. \& Foxcroft, G.R. (1990) A comparison of preovulatory follicles in Meishan and Large White pigs. Symposium sur le porc Chinois, pp. 41-42. Eds M. Molénat \& C. Legault. INRA, Station de Génétique quantitative et appliquée, Jouy en Josas, France.

Bolet, G., Martinat-Botte, F., Locatelli, A., Gruand, J., Terqui, M. \& Berthelot, F. (1986) Components of prolificacy in hyperprolific Large White sows compared with the Meishan and Large White breeds. Génétique Sélection et Evolution 3, 333-342.

Haley, C.S. \& Lee, G.J. (1990) Genetic components of litter size in Meishan and Large White pigs and their crosses. Proceedings of 4th World Congress on Genetics Applied to Livestock Production XV, 458-461.

Haley, C.S., Lee, G.J., Wilmut, I., Ashworth, C.J., Aitken, R.P. \& Ritchie, W. (1990) British studies of the genetics of prolificacy in the Meishan pig. In Symposium sur le porc Chinois, pp. 85-97. Eds M. Molénat \& C. Legault. IRNA, Jouy en Josas, France.

Pope, W.F., Wilde, M.H. \& Xie, S. (1988) Effect of electrocautery of nonovulated day 1 follicles on subsequent morphological variation among day 11 porcine embryos. Biology of Reproduction 39, 882-887.

Pope, W.F., Xie, S., Broermann, D.M. \& Nephew, K.P. (1990) Causes and consequences of early embryonic diversity in pigs. Journal of Reproduction and Fertility Supplement 40, 251-260.

Ritchie, W., Haley, C.S., Ashworth, C.J., Aitken, R.P. \& Wilmut, I. (1989) A comparison of rate and consistency of embryo development in Meishan and Large White pigs. Journal of Reproduction Fertility Abstract Series 4, Abstract 33.

Sellier, P. (1976) The basis of crossbreeding in pigs; A review. Livestock Production Science 3, 203-226.

Terqui, M., Bazer, F.W. \& Martinat-Botte, F. (1990) Mechanisms involved in the high prolificacy of the Meishan breed. In Symposium sur le porc Chinois, pp. 19-32. Eds M. Molénat \& C. Legault. INRA, Jouy en Josas, France.

Wilmut, I., Sales, D. I. \& Ashworth, C. J. (1986) Maternal and embryonic factors associated with prenatal loss in mammals. Journal of Reproduction and Fertility 76, 851-864.

Wilmut, I., Haley, C.J., Ashworth, C.J., Aitken, R.P. \& Ritchie, W. (1990) Proceedings of the 4th World Congress on Genetics Applied to Livestock Production XVI, 347-350.

Received 15 January 1991 